NASA Contractor Report 185140

AIAA-89-2140

\title{
A Supersonic Through-Flow Fan Engine Airframe Integration Study
}

(VASA-CR-1.5140) A JUPFRSONIC THRUUGH-FL W FAN - VGTHR AIDFRAME INTRGATION STUDY rinal NOU-10004 Report (cverdrup Technology) $11 \mathrm{p} \mathrm{CSCL} 01 \mathrm{~A}$

Paul J. Barnhart

Sverdrup Technology, Inc.

NASA Lewis Research Center Group

Cleveland, Ohio

September 1989

Prepared for

Lewis Research Center

Under Contract NAS3-25266 


\section{,}




\section{A SUPERSONIC THROUGH-FLOW FAN ENGINE AIRFRAME INTEGRATION STUDY}

Paul J. Barnhart*

Sverdrup Technology, Inc.

NASA Lewis Research Center Group

Cleveland, Ohio $\mathbf{4 4 1 3 5}$

\section{ABSTRACT}

A study is undertaken to investigate the engine airframe integration effects for supersonic through-flow fan engines installed on a Mach 3.20 supersonic cruise vehicle. Six different supersonic throughflow fan engine installations covering the effects of engine size, nacelle contour, nacelle placement, and approximate bypass nacelle placement, and approximated. The different supersonic through-flow fan installations are compared with a conventional turbine bypass engine configuration on the same basic airframe. The supersonic throughflow fan engine integrations are shown to be comparable to the turbine bypass engine configuration on the basis of installed nacelle wave drag. The supersonic throughflow fan engine airframe integrated vehicles have superior aerodynamic performance on the basis of maximum liftto-drag ratio than the turbine bypass engine installation over the entire operating Mach number range from 1.10 to 3.20. When approximate bypass plume modeling is included, the supersonic through-flow fan engine configuration shows even larger improvements over the turbine bypass engine configuration.

\section{NOMENCLATURE}

$\begin{array}{ll}\text { BPR } & \text { bypass ratio } \\ C D & \text { drag coefficient, D/qS } \\ C L & \text { lift coefficient, L/qS } \\ D & \text { drag } \\ \text { L } & \text { lift } \\ M & \text { Mach number } \\ q & \text { dynamic pressure } \\ \text { S } & \text { reference area } \\ \text { Subscripts } & \\ f & \text { friction } \\ \text { W } & \text { wave }\end{array}$

\section{INTRODUCTION}

In perusing the technologies required for efficient long range supersonic cruise aircraft, NASA has sponsored a number of studies to identify suitable propulsion system concepts. In the past, conventional and variable cycle engines were considered the most likely candidates. With renewed

*Supervisor, Aerospace Analysis Section, Member AIAA interest in civilian supersonic cruise flight in the Mach 2 to 5 speed range, another engine design has shown the potential for higher performance than more conventional engines. The supersonic through-flow fan engine has been analyzed in other studies ${ }^{1.3,00}$ and indications are that this concept promises significant reductions in specific fuel consumption. one possible configuration of this engine, shown in Figure 1, incorporates a single stage supersonic through-flow fan. This turbomachinery element operates with supersonic axial Mach numbers at both the fan face and stator exits.

The engine design in Figure 1 has
components arranged similar to a
conventional turbofan engine.
axisymmetric primary inlet delivers
supersonic air to the fan face. Behind the
stator exit is a core inlet which bypasses
some of the fan exit flow and diffuses the
remaining air to subsonic speeds, entering
the engine core spool. The fan spool is
powered by a second turbine following the
core spool. Finally, the core air flow is
discharged through a nozle. An attractive
feature of the supersonic through-flow fan
engine is the short all-supersonic inlet,
resulting in higher recovery and lower
weight and inlet aerodynamic drags. The
single stage fan features lower weight and
cost, as well as more rugged blading.
Another desirable aspect of the engine
cycle is that the bypass ratio decreases
with increasing flight Mach number,
providing higher cruise thrust.

Reference 3 shows that much of the improved specific fuel consumption for supersonic through-flow fan engines results from potential improvements in installation efficiencies for long range supersonic cruise applications. The possible improvements in inlet performance with supersonic through-flow fan engines has been shown in reference 4. This study addresses the engine airframe integration characteristics for supersonic through-flow fan propulsion systems. Six different supersonic through-flow fan engine installations are examined in this study. The effects of engine size, nacelle contouring, nacelle placement, and approximate bypass plume modeling are investigated. Additionally, the supersonic through-flow fan (STFF) nacelle installations are compared with a conventional turbine bypass engine (TBE) nacelle installation on the basis of installed wave drags and maximum lift to drag ratios for complete engine airframe 
integrated vehicle aerodynamics. All of the engine airframe combinations studied have the same design Mach number of 3.20 and are axisymmetric wing podded engine installations.

\section{METHOD OF ANALYSIS}

The sequence of analyses used in this study is to first define the nacelle and vehicle geometries, second compute the nacelle installed wave and friction drags, and finally assess the integrated engine and airframe vehicle. aerodynamic performance. The geometries for the TBE nacelle and the basic airframe are taken from the sample case for the computer codes of references $5-7$. The geometric definitions are represented as wire frame solid models, and Figure 2 shows the TBE nacelle shape used in this study for comparison purposes. Preliminary STFF nacelle designs have been derived from first order engine layouts performed at NASA Lewis ${ }^{4}$. A wire frame of the basic STFF nacelle geometry is shown in Figure 3 . The STFF nacelle geometry is more complex than the TBE in that the STFF nacelle is comprised of three distinct surfaces. The forward part is the fan nacelle. Following this is the bypass exhaust plume, which in Figure 3 is one-quarter cut away to show the core nacelle surface below. The fan and core nacelles are solid surfaces while the bypass plume is a flow streamline boundary. The STFF inlet centerbody and core nozzle plug, though shown in Figure 3 for association with the layout in Figure 1 , are neglected in the analyses in this study.

Computations assessing nacelle airframe integration effects were performed using the computer programs from references 5-7. The nacelle wave drags were calculated by the near-field wave drac program which computes zero-lift thickness pressure distributions for wing-bodynacelle contigurations in supersonic flow. Pressure coefficients, computed by linearized supersonic theory for wings and by Lighthill's perturbation theory for bodies and nacelles, are integrated over the surface areas to calculate isolated wave drags for each component in the configuration geometry. Superposition methods are then used to calculate the interference drags resulting from the pressure field of one component acting on the surfaces of the other components. In calculating the total wave drag for a nacelle configuration, the installed drag is the sum of the isolated nacelle wave drag and the nacelle interference wave drags. The nacelle interference wave drags include: nacelle-on-wing, nacelle-onfuselage, fuselage-on-nacelle, wing-onnacelle, nacelle-on-nacelle, and nacelle image effects. The nacelle skin friction drags were calculated using the method of Sommer and short ${ }^{5}$.
The procedure used to assess the various engine airframe integrations is as follows. In all cases a common wingfuselage-tail geometry is used. Vertical fins were neglected in this study. Specific nacelle geometries were read into the programs ${ }^{5-7}$ with the basic airframe. The skin friction for all components was then calculated over the supersonic operating Mach number range 1.10 to 3.20 . Next a drag-due-to-lift analysis ${ }^{5-7}$ at the Mach 3.20 cruise condition was conducted that provided wing lifting pressure loads including the effects from the nacelles. A wing design optimization ${ }^{5-7}$ was then used to reflex the wing camber to best integrate the particular nacelle geometries specified at Mach 3.20 cruise. The airframe geometry was then fixed and the near-field wave drag program used over the Mach number range 1.10 to 3.20 to compute the nacelle effects including isolated, interference, and installed wave drags.

The above procedure was first applied to the TBE nacelle configuration. The results of the TBE nacelle wave drag calculations were then used to compare with each of the subsequent STFF nacelle configurations analyzed by the same process. BY comparing STFF and TBE nacelle wave drags, the most effective STFF nacelle configurations and integration variables could be assessed. This process was applied to six different STFF nacelle configurations covering variations in nacelle size, nacelle contouring, nacelle placement, and approximate bypass plume effects. Rather than perform a similar installation optimization procedure for the TBE, the already optimized installation geometry from references $5-7$ was adopted for the TBE configuration.

To assess the integrated engine airframe vehicle performance, the maximum lift-to-drag ratios were calculated over the operating Mach number range 1.10 to 3.20. The basic airframe without nacelles was analyzed by the full vehicle panel method program APAS ${ }^{8,9}$. The drag polars obtained from APAS were then adjusted by shifting the polars by sum of the nacelle installed wave and skin friction drag coefficients to yield engine airframe integrated aerodynamic characteristics for each particular nacelle configuration examined. From these modified drag polars the maximum $L / D$ was computed and comparisons drawn between various engine airframe integrations.

\section{RESULTS AND DISCUSSION}

\section{TBE Configuration}

Figure 4 shows the wire frame model of the TBE configuration without hidden line removal. The airframe has an arrow wing with camber and twist. The fuselage is circular in cross section and area ruled. A small horizontal tail is included. 
however, no vertical fins are present in the model wire frame. Four axisymmetric TBE nacelles are mounted beneath the wing as shown. The overall length of the airframe is $89.92 \mathrm{~m}(295.0 \mathrm{ft})$ and the wing span is $40.39 \mathrm{~m}(132.5 \mathrm{ft})$. The TBE nacelies are $10.68 \mathrm{~m}(35.04 \mathrm{ft})$ long and have a cowl lip diameter of $1.75 \mathrm{~m}(5.73$ $f t)$. The reference area, $s$, for this airframe is $919.6 \mathrm{~m}^{2}\left(9898 \mathrm{ft}^{2}\right)$.

The results of the TBE installation are shown in Figure 5 . Three nacelle wave drag coefficients, isolated, interference, and installed are plotted as functions of flight Mach number. The drag coefficients are the sum of all four nacelles and thus represent the total wave drag effect of the nacelle configuration. The uppermost curve is the wave drag coefficient for the isolated nacelles without the presence of the airframe. This drag exhibits a slight increase with decreasing Mach number. The lowermost curve is the wave drag coefficient for the interference effects on the nacelles resulting from the presence of the airframe. Above approximately Mach 1.30 this drag term has a negative value and is thus a thrust force on the nacelles. This behavior is sometimes termed a favorable interference. Below Mach 1.30 the interference effect is positive in value and thus contributes additional drag, or an unfavorable interference. The sum of the isolated and interference drag coefficients is the installed wave drag coefficient. This last curve shows that for Mach numbers of 2.00 and above the isolated nacelle wave drag is effectively cancelled by the interference wave drag. Below Mach 2.00 the installed wave drag rises with falling Mach number, reaching the greatest value at Mach 1.10. Thus for most of the supersonic flight Mach number range this TBE configuration is very efficient.

\section{STFF Confiquration}

The first of the STFF configurations (STEF-1) is shown in Figure 6. Notice that in this wire frame only the fan nacelles have been modeled. The effects of the bypass plume are investigated later, and this nacelle geometry is an initial approximation. These nacelles are located in the same position as the TBE nacelles. The nacelle sizing for the STFF-1 configuration is taken from the results of mission studies ${ }^{10}$. For the largest STFF engines examined in reference 10 , the nacelle cowl lip diameter is $2.01 \mathrm{~m}(6.58$ $f t)$. A very simple shape is used here for the fan nacelle, a straight conic followed by a cylinder, having an overall length of $3.65 \mathrm{~m}(12.0 \mathrm{ft})$. This size nacelle corresponds to a STFF engine having a design BPR of $0.75^{10}$.

The basic airframe used here is the same as that in the TBE configuration. As in the TBE case, a wing design optimization was employed to best adjust the wing camber to accommodate the STFF nacelles. In this manner, slight camber distributions specifically designed for the TBE nacelles are not adversely affecting the integration analysis for the STFF-1 configuration, and comparisons based on best possible nacellewing geometries may be made. This wing camber optimization procedure has also been applied to all other configurations to be discussed later.

The results for the STFF-1 configuration are presented in Figure 7 . As in Figure 5 for the TBE, three solid curves are shown for the isolated, interference, and installed wave drags for the STFF-1. The three dashed curves are the same plats for the TBE configuration shown previously. The isolated wave drag coefficient is sightly lower than the TBE values above Mach 2.00 and slightly higher below Mach 2.00. The favorable interference effects are roughly half as strong for the STFF-1 as they were for the TBE above Mach 2.00. The STFF-1 configuration does show, however, about half of the unfavorable interference effects at Mach 1.10 as does the TBE. As a result, the installed wave drag coefficient for the STFF-1 is higher than the TBE for most of the Mach number range, with a slightly lower value seen at Mach 1.50. Thus the isolated wave drag is not cancelled by the interference effects for STFF-1 as it is for the TBE in the Mach 2.00 to 3.20 range. The installed wave drags are roughly comparable at the Mach 1.10 transonic point, the STFF-1 being only slightly higher than the TBE.

\section{Bypass Ratio Effects}

For STFF engines, as for any bypass engine, the design bypass ratio tends to have an important effect in sizing the engine ${ }^{10}$. The next two STFF configurations examined (STFF-2 and STFF-3) were each essentially the same configuration as the STFF-1, but with slightly smaller nacelles. The STFF-2 nacelle corresponds to a design $B P R$ of 0.50 and has a cowl lip diameter of $1.90 \mathrm{~m}(6.23 \mathrm{ft})$ while the STFF-3 nacelle has a design BPR of 0.25 and cowl 1 ip diameter of $1.80 \mathrm{~m}(5.90 \mathrm{ft})$. For both configurations the nacelle was again modeled by the fan nacelle only, and the nacelle lengths are scaled in accordance to the nacelle diameters. As was the case for the nacelle configuration, STFF-2 and STFF3 have the nacelles in the same location as the TBE configuration.

The results of the changing nacelle size as a function of the design BPR are presented in Figure 8 . This plot shows only the installed nacelle wave drag coefficients for the STFF-1, STFF-2, and STFF-3 configurations (bypass ratios of $0.75,0.50,0.25$ respectively). The isolated and interference wave drags for the STFF-2 and STFF-3 show the same characteristics as found for the STFF-1 in Figure 7. The effects of changing $B P R$ are seen to shift the installed drag coefficient lower with decreasing BPR (and 
size), but not to change the characteristic trends of the curves. The largest absolute shift in the installed wave drag is seen at Mach 1.10, while at the design point, Mach 3.20, the effect of BPR is the least. Thus, for similarly shaped STFF nacelles, changing BPR has the greatest impact on the installed wave drag only at the lowest supersonic Mach numbers.

\section{Nacel le Contouring}

The next STFF configuration examined the effect of nacelle contouring. Figure 9 shows the STFF-4 configuration wire frame. In this case the nacelle cowl lip diameter is the same as the STFF-1 and the nacelles are in the same location. The STFF-4 nacelle contours are gradually curved to a cylinder rather than sharply broken from a conic to a cylinder in only two segments as are the STFF-1 nacelles.

The results of the contoured nacelles aie shown in Figure 10 . The isolated wave drag coefficient is slightly greater than the TBE. The interference wave drags are very similar in both magnitude and trend between the STFF-4 and the TBE configurations. Recall that for the STFF1 simply contoured nacelles, the favorable interference effects were roughly half those of the TBE. The installed wave drag for the STFF-4 parallels the TBE curve approximately. The installed wave drags are neally constant for the $5 T F F-4$ from Mach 2.00 to 3.20 , though slightly larger than the TBE. At Mach 1.10, however, the cumbination of a greater isolated wave drag and an unfavorable interference effect results in a larger installed wave drag than the TBE configuration. It is desirable to minimize this transonic drag rise characteristic since most supersonic ajrcraft tend to size their engines at this operating point.

Nisel le Placement

In an effort to lessen the increased transonic drag rise of the STFF-4 contiguration, rather than resizing the nacelle as was previously done, variations in nacelle placement are investigated for the STFF-5 configuration shown in Figure 11. The contoured nacelles of the STFF-4 cuse are shifted outward and sightly aft. the inboard nacelles are moved outboard from the fuselage, while the outboard nacelles are moved further outboard from the inboard nacelles. This approach attempts to lessen the pressure field interactions between components at the low supersonic Mach numbers. rhe preclse nacelle placements were iterated until an acceptable configuration was found.

The results of the nacelle placement for the STFF-5 configuration are found in Figure 12. Contrasting Figures 12 and 10 , the greatest change is a substantial improvement in the interference wave drags for the STFF-5 over the STFF-4 configuration at Mach 1.10 . This reduction in interference wave drag at this Mach number yields a configuration for the STFF5 which has the same installed wave drag as the TBE. There is no adverse penalty in the higher supersonic Mach numbers for this placement of nacelles, and thus by widening the nacelle spacing for STFF installations, transonic installed wave drags can be maintained at the same levels as those of the TBE configuration.

\section{Bypass Plume Effects}

The presence of the bypass exhaust plume may possibly have a beneficial effect on the installed STFF nacelle wave drag characteristics. If the plume is
expanding, then the change in the surrounding air flow streamlines will produce an effective pressure field as if a solid boundary were present. This plume pressure field interacting with the other components of the aircraft could have a favorable effect. Additionally, since the plume is not a solid surface, there will not be any additional isolated wave drag generated, and the result could be a reduced installed wave drag configuration.

To explore the potential effects of a bypass plume, the STFF-6 configuration shown in Figure 13 is used. In this configuration, the fan nacelles used in the STFF-1 case (BPR of 0.75) are used here as the forward portion of the STFF- 6 nacelles. Following the fan nacelles is a slightly expanding bypass plume modeled here as a solid surface. This plume surface is treated as a solid body for all interference terms which would result from the presence of the plume, but the interference terms which result from the effects of other component's pressure fields acting on the plume are instead replaced by the calculations from the STFF1 case without the plume. Thus, the plume may impart a pressure field upon other components, but may not contribute any effects by other components acting upon the plume itself. In this way the effects of the plume are approximated for the STFF-6 configuration. Also, the plume shape is assumed constant over the Mach number range.

The results of the bypass plume approximations are shown in Figure 14 . As anticipated the interference effects are much more favorable than the STFF-1 case in Figure 7. The plume in the STFF-6 configuration always maintains a favorable interference effect, while the isolated wave drag is only the result of the solid surface of the fan cowl. The result is that the STFF-6 installed wave drag is nearly zero from Mach 1.80 to 3.20 . This is comparable to the TBE configuration. Below Mach 2.0 the STFF-6 installed wave drag is significantly lower than the TBE even at the Mach 1.10 point. Thus the presence of a bypass plume may have a very important contribution in STFF engine airframe integrations which could perform better than TBE configurations. 


\section{Vehicle Performance}

since nacelle installed zero-lift wave drags are not the complete description of engine airframe integrations, another comparison is necessary to assess the potential available in using STFF engines. Figure 15 presents the nacelle skin friction coefficients for the TBE, STFF-1, $S T F F-5$, and $S T F F-6$ configurations. In all cases the STFF nacelles have considerably lower friction drags as a result of their smaller surface areas. The friction drag on the STFF core nacelle is not included in this plot. Since the core nacelle is washed by the bypass plume, calculation of the friction drag on this surface would require knowledge of the bypass exhaust flow properties. By combining the installed nacelle wave and skin friction drag coefficients, the net effect of the nacelle integration can be used to adjust drag polars from a bare airframe (without nacelies) to give the aerodynamic performance of the integrated engine airframe combination.

The bare airframe aerodynamics are computed by the APAS panel method program and the resulting drag polars for the configuration, shown in Figure 4 but without nacelies present, are shown in Figure 16. These drag polars are then adjusted by the nacelle installed wave drag coefficients and the nacelle skin friction coefficients. From these new drag polars for the integrated engine airframe combination the maximum $L / D$ may be computed. The results for the TBE, STFF-1, STFF-5, and STFF-6 configurations are shown in Figure 17 . All of the STFF configurations are observed to have higher values of maximum $L / D$ than the TBE configuration. of the three STFF configurations, the STFF- 6 case approximating the plume effects is found to have significantly better aerodynamic performance than the TBE configuration, $2.49 \%$ and $4.14 \%$ higher at Mach 3.20 and 1.10 respectively. However even the STFF configurations analyzed neglecting the plume effects out performed the TBE. Thus the potential for significant aerodynamic improvements is demonstrated for the successful integration of STFF engine installations on a supersonic cruise aircraft.

\section{SUMMARY}

The study undertaken to show the effects of STFF engine airframe integration examines six different STFF installations covering the effects of engine size, covering the effects of placement and approximate bypass plume modeling. The results of these STFF configurations are compared against a TBE on the basis of nacelle wave drags and integrated engine airframe vehicle maximum $L / D$ performance characteristics. The configurations are examined over the supersonic Mach number range of 1.10 to 3.20 .

In all the STFF cases, installed wave drags are found to be comparable to those for the TBE configuration. The STFF cases are also found to have substantially lower skin friction drags than the TBE. When comparing the integrated engine airframe vehicle maximum L/D, all of the STFF configurations showed higher values over the entire Mach number range examined. The STFF-6 case approximately modeling the bypass plume effects showed the largest improvement in maximum $L / D$. Yet even when the bypass plume effects are ignored the STFF configurations still have higher values of maximum $L / D$ than the $T B E$.

This investigation shows some of the potential improvements in vehicle aerodynamic performance for well integrated STFF engine airframe configurations. Additional effects in STFF nacelle design need to be examined to elucidate the full need to be exar engine airframe integrations. optimal combinations of nacelle contour, engine size, nacelle placement and wing camber need to be studied in more depth. The accurate modeling of the bypass plume needs to be pursued since this effect, though only approximately modeled, shows the greatest improvements in integrated vehicle performance.

\section{ACKNOWLEDGEMENT}

The author wishes to thank Jim Davic, Research Engineer, Aerospace Analysis Section, Sverdrup Technology, and Jim Grabowski, NASA Lewis student Trainee, University of Dayton, for their contributions to this paper in generating the basic vehicle aerodynamic performance using APAS. This research was sponsored by the NASA Lewis Research center, Cleveland, onio, under contract NAS3-25266.

\section{REFERENCES}

1. Trucco, H., "Study of Variable Cycle Engines Equiped with Supersonic Fans, Final Report", ATL TR 201 Advanced TechnologY Laboratóries Inc., NAS3-17559, NASA CR134777,1975 .

2. Franciscus, L. C.. "Supersonic Through-Flow Fan Engines for Supersonic cruise Aircraft", NASA TM-78889, 1978.

3. Franciscus, L. C., "The Supersonic Through-Flow Turbofan for High Mach Propulsion", NASA TM-100114, AIAA-87-2050, July, 1987.

4. Barnhart, P. J., "A Preliminary Design Study of Supersonic Through-Flow Fan Inlets", NASA CR-182224, 1988.

5. Middleton, W. D., and Lundry, J. L., 
"A Computational System for Aerodynamic Design and Analysis of Supersonic Aircraft, Part 1 - General Description and Theoretical Development", NASA CR-2715, 1976.

6. Middleton, W. D., Lundry, J. L., and Coleman, R. G." "A Computational System for Aerodynamic Design and Analysis of Supersonic Aircraft, Part 2 - User's Manual", NASA CR-2716, 1976.

7. Middieton, W. D., Lundry, J. L., and Coleman, R. G., "A Computational System for Aerodynamic Design and Analysis of Supersonic Aircraft, Part 3- Computer Program Description", NASA CR-2717, 1976.

8. Bonner, E., Clever, W., and Dunn, K., "Aerodynamic Preliminary Analysis System, Part I Theory", NASA CR-165627, 1981.

9. Divan, P., "Aerodynamic Preliminary Analysis system, Part II User's Manual", NASA CR-165628, 1981.

20. Franciscus, L. C., and Maldonado, J. J., "Supersonic Through-Flow Fan Engine and Aircraft Mission Performance", AIAA-892132, July, 1989.

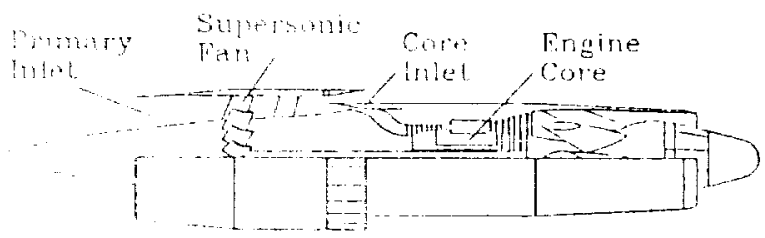

Iillite i: Supersonic through-flow fan engine concept.

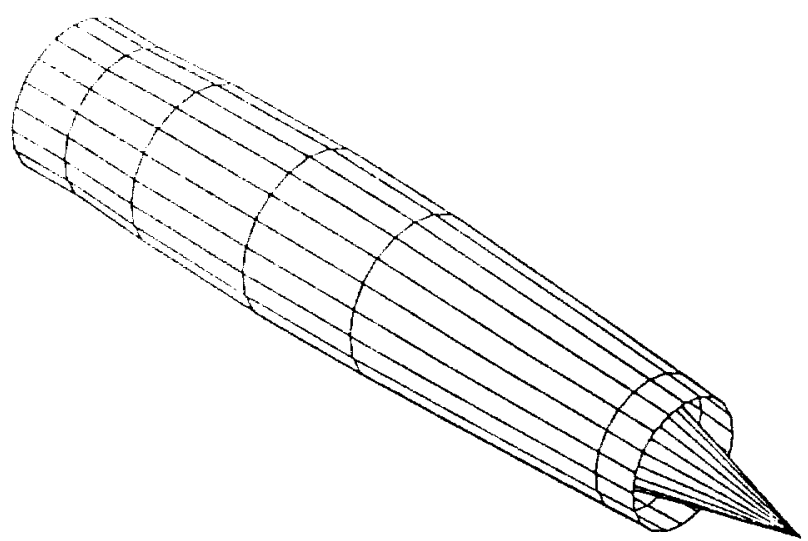

Fignure 2: TBE nacelle wire frame.

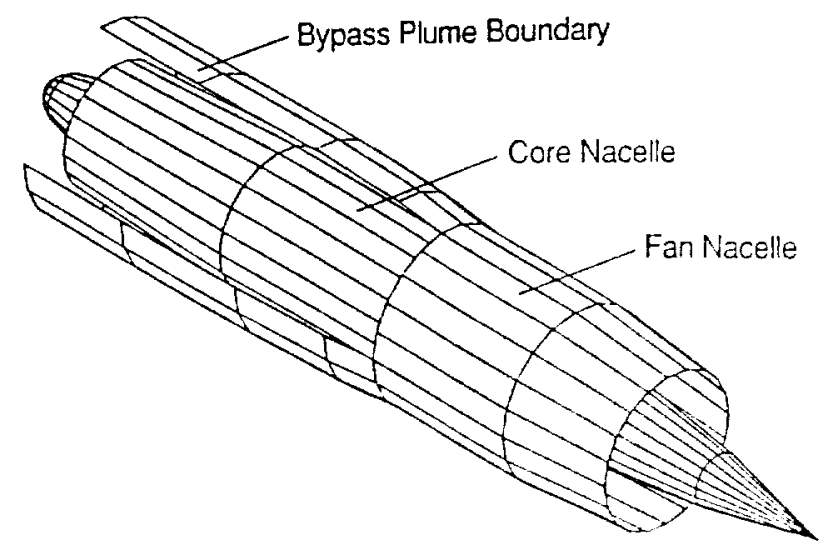

Figure 3: STFF nacelle wire frame.

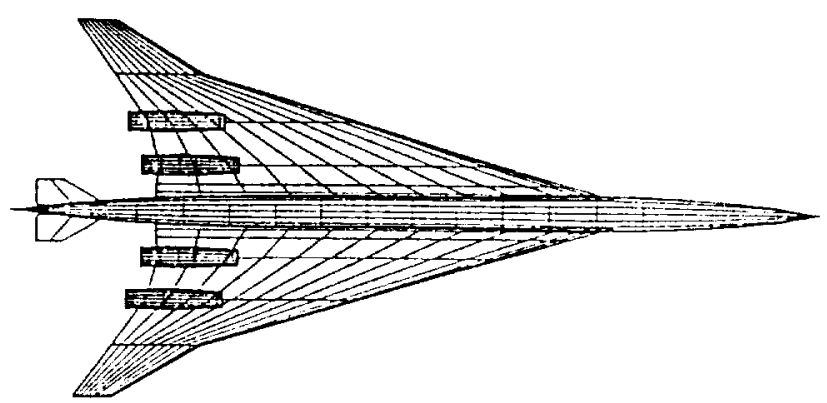

Figure 4: TBE configuration wire frame.

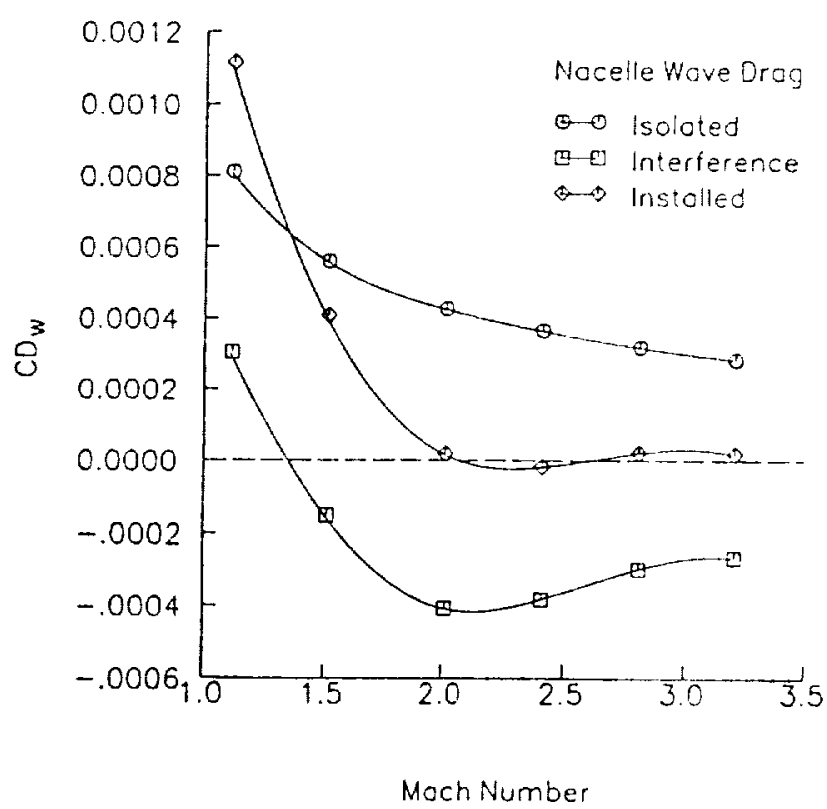

Figure 5: TBE configuration nacelle wave drags. 


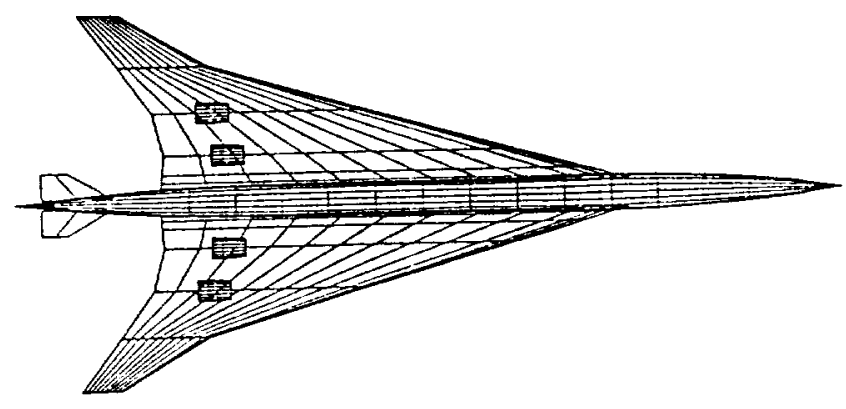

Figure 6: STFF-1 configuration wire frame.

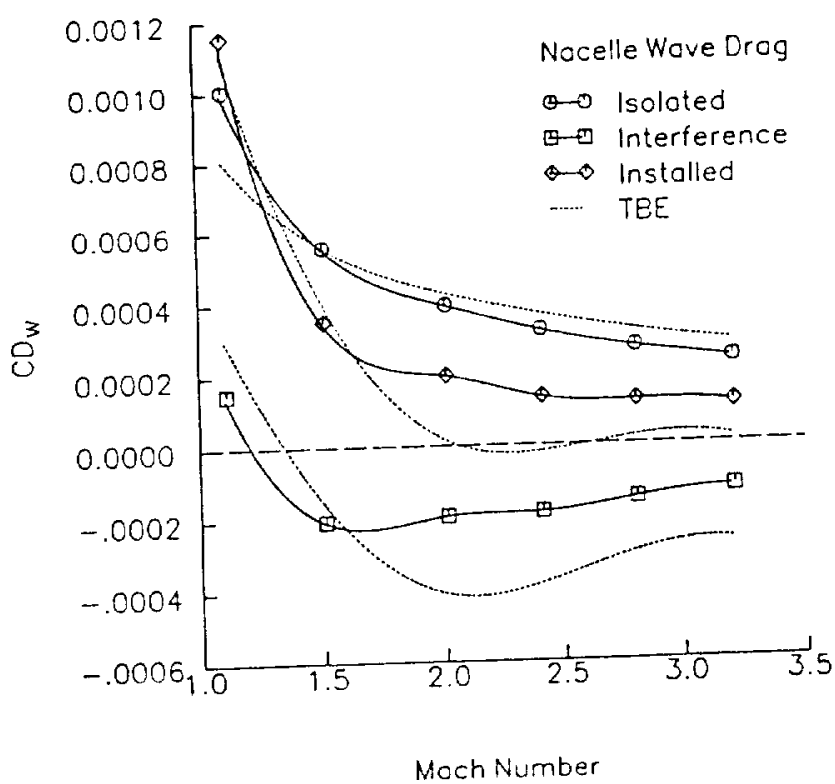
Figure 7: STFF-1 configuration nacelle
wave drags.

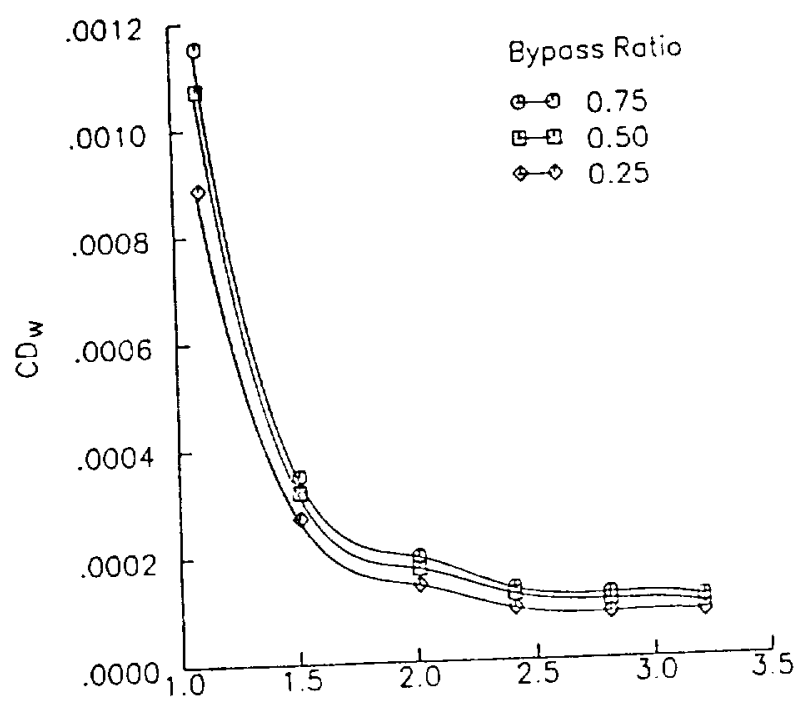

Mach Number

Figure 8: Design BPR effect on installed
nacelle wave drag.

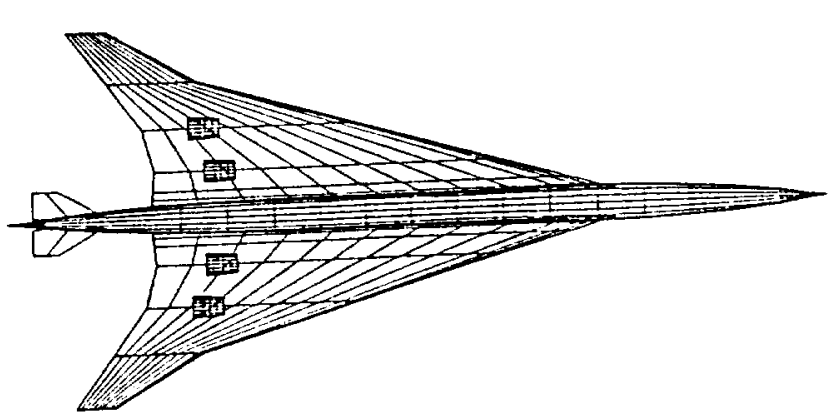

Figure 9: $\mathrm{STFF}^{-4}$ configuration wire frame. 


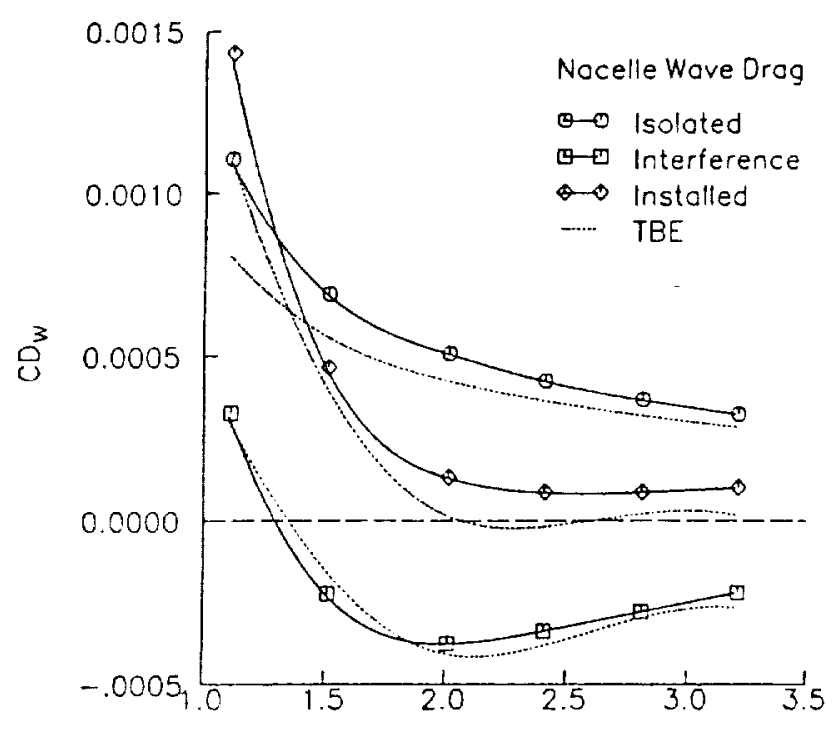

Moch Number

Figure 10: STFF-4 configuration nacelle wave drags.

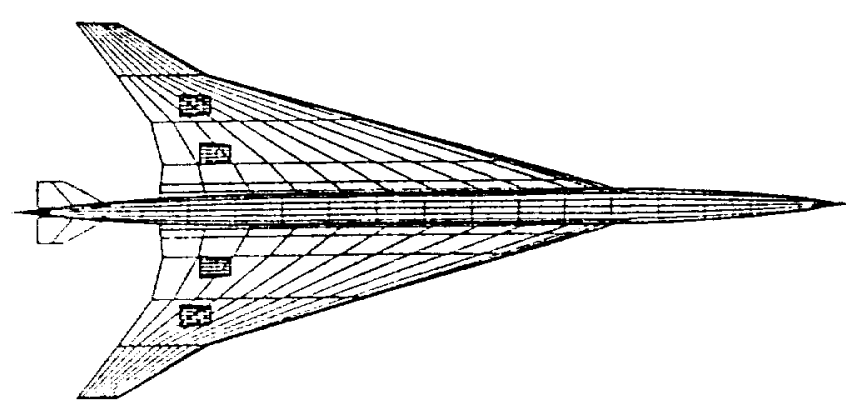

Figure 11: STFF-5 configuration wire frame.

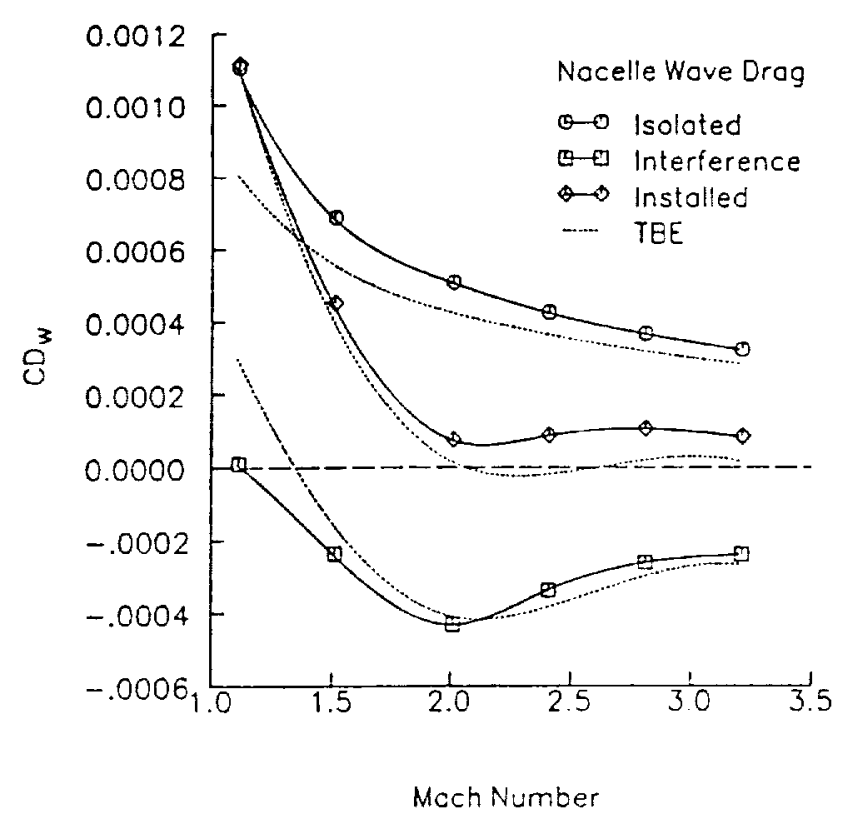

Figure 12: STFF-5 configuration nacelle wave drags.

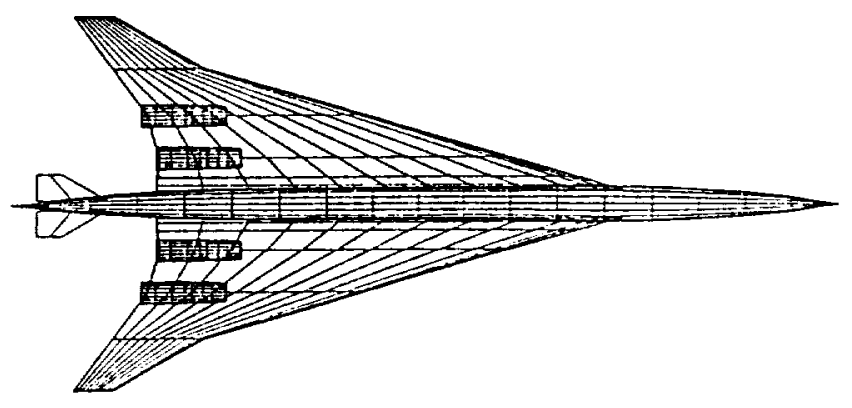

Figure 13: STFF-6 configuration wire frame. 


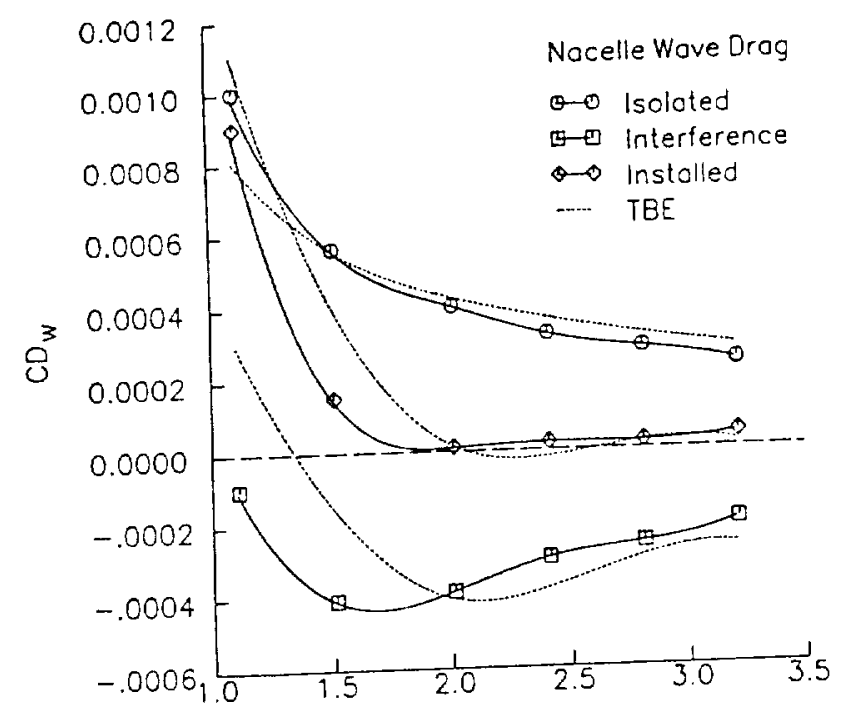

Mach Number Figure 14: $\begin{aligned} & \text { STFF-6 configuration nacelle } \\ & \text { wave drags. }\end{aligned}$

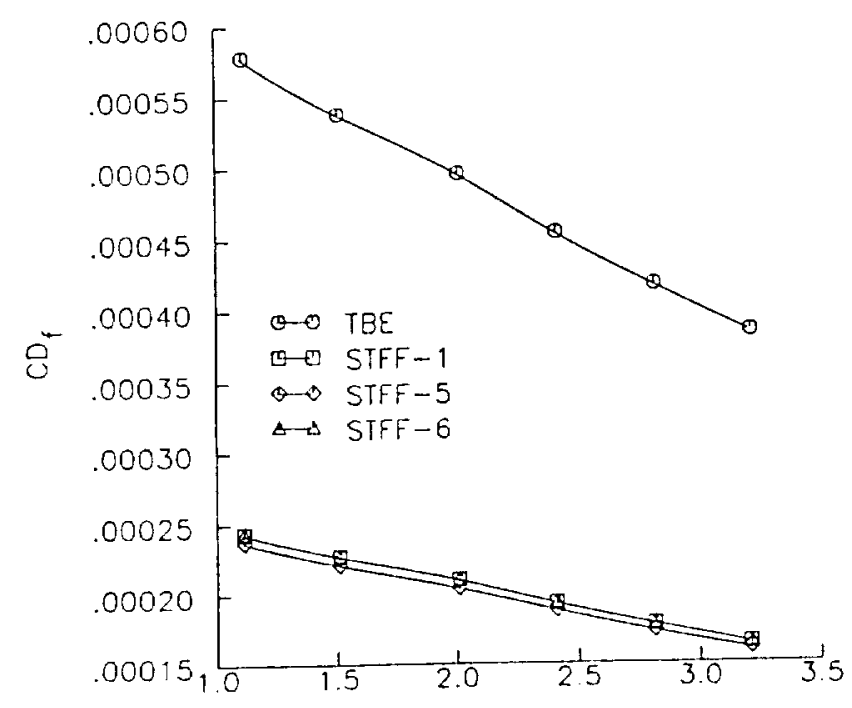

Mach Number

Figure 15: Nacelle skin friction drags.

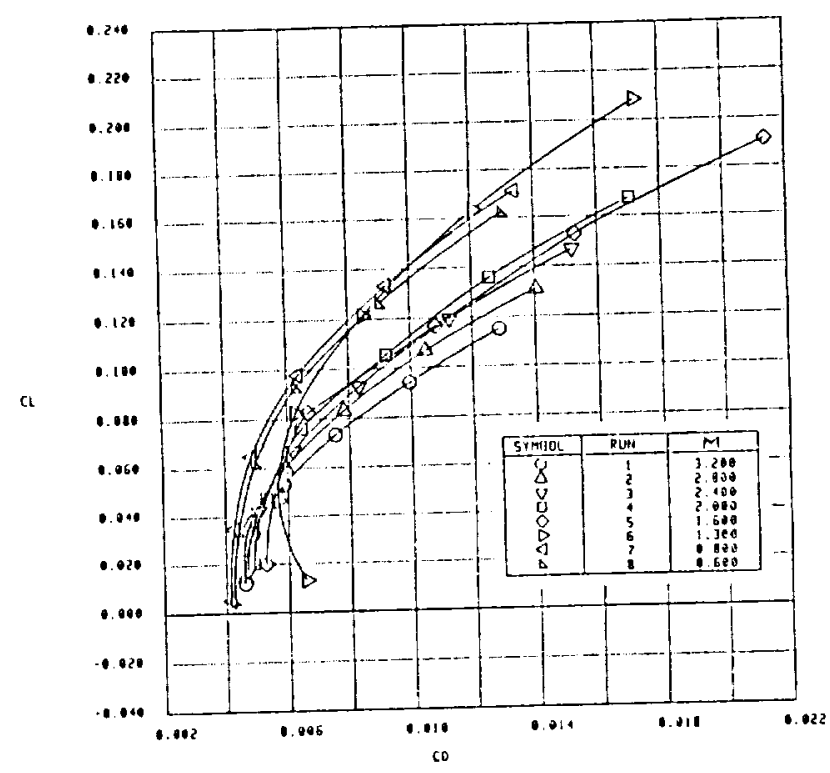

Figure 16: Bare airframe (without nacelles) drag polars.

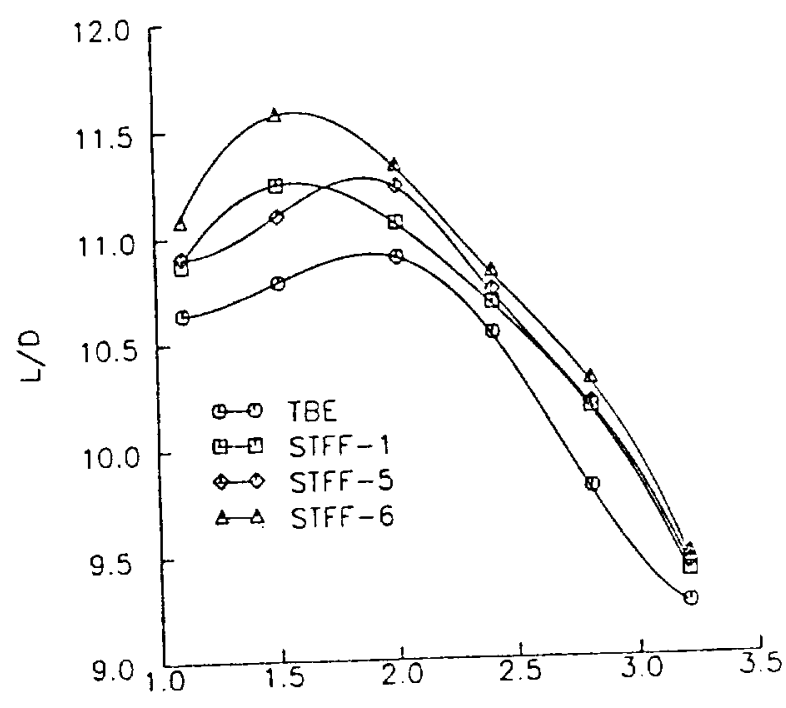

Mach Number

Figure 17: Integrated engine airframe maximum $\mathrm{L} / \mathrm{D}$. 


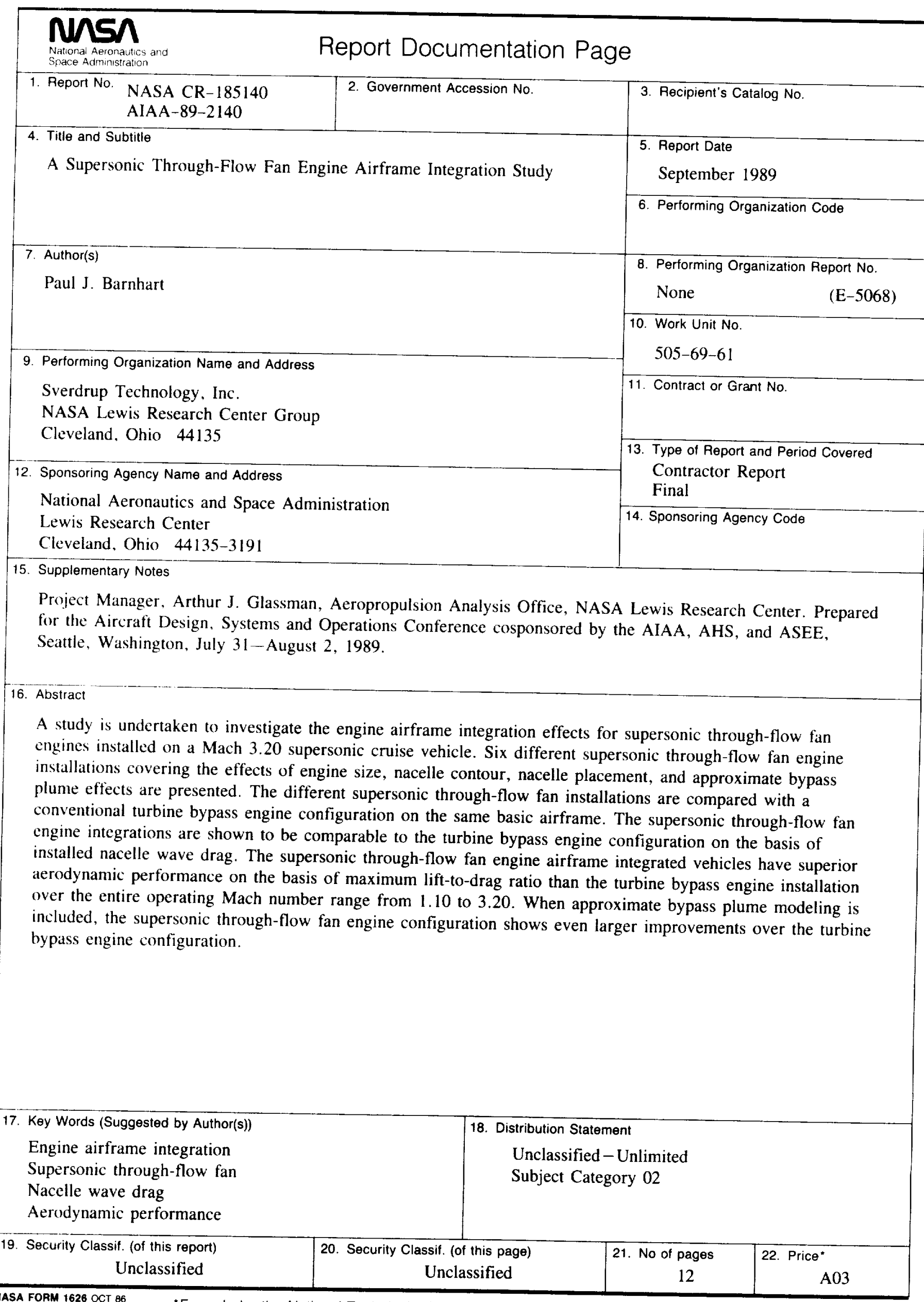


National Aeronautics and

Space Administration

Lewis Research Center

Cleveland, Ohio 44135

OHicial Business

Penalty for Private Use $\mathbf{\$ 3 0 0}$
FOURTH CLASS MAIL

ADDRESS CORRECTION REQUESTED
|||||

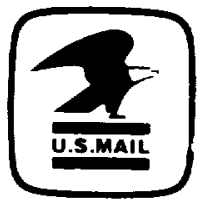

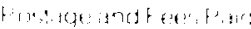

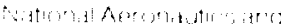

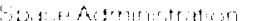

$\operatorname{in}\left(\sin 4^{1}\right)$ 